\title{
Interpretation of Gas Chimney Volumes
}

\author{
Fred Aminzadeh ${ }^{1}$, David Connolly ${ }^{1}$ and Paul de Groot ${ }^{2}$ \\ ${ }^{1}$ dGB-USA, 2500 Tanglewilde, Suite 120, Houston, TX, 77063 faz@dgbusa.com \\ ${ }^{2} d G B$ BV, Boulevard 1945-24, 7511 AE Enschede, The Netherlands, paul@dgb.nl
}

\section{Summary}

In this paper we describe how seismically derived gas chimneys can be used to determine hydrocarbon migration paths. The emphasis will be on how to interpret chimney cubes. Through several case history examples, we will show chimney cubes can reveal vertical hydrocarbon migration paths that can be interpreted from their source into reservoir traps all the way to the surface. We will highlight distinguishing features of chimneys for oil-prone versus gas-prone prospects, and those related to separating active fault migration pathways. Further, we will show chimneys can support charging of shallow reservoirs. Our understanding of the petroleum system can improve by combining gas chimney data with other information. As such a chimney cube can be seen as a new exploration tool.

\section{Introduction}

Gas clouds and gas chimneys have often been considered as a source of seismic noise that degrades the quality of seismic reflection events. Many efforts have been devoted to deal with this problem and filter out the impact of gas clouds and provide interpretable sections by imaging through them. Aside from different filtering techniques, tomography, and shear wave information have been used, for example, Dunbar (1998) and Englehart (2001), to accomplish this. While this paper also deals with gas clouds and gas chimneys, the main focus is to highlight such events and establish a link between chimney characteristics (occurrence, type and extent) and different geological features or exploration questions. Among issues to be addressed are trap integrity, hydrocarbon type and active migration pathways. For other applications of chimneys such as their role in detecting geohazards and seeps see Connolly et al (2002).

\section{Review of the procedure}

A chimney cube is a 3D volume of seismic data, which highlights vertical chaotic behavior of seismic characters. We will give a brief description of the methodology the details of which can be found in Meldahl et al, (1998) and Aminzadeh et al (2001). Aside from the conventional single trace attributes such as amplitude, frequency and energy, the "directional attributes" such dip angle variance with different step outs, similarity measures, and dip-azimuth based contrast enhancement are calculated. A specially designed supervised Multi-Layer-Perception (MLP) neural network is used to select a subset of these attributes that are most discriminatory in distinguishing between chimneys and non-chimneys. The neural network is trained on examples of chimneys and non-chimneys (background) selected by the interpreter.

The discriminatory power of attributes is greatly enhanced if they are calculated using dip-steering, where local dip information is utilized. For example the similarity attribute, which calculates the normalized Euclidean distance between two or more trace segments, is much better defined if the trace segments belong to the same seismic event. This requires knowledge of the local dip and azimuth, which can be calculated using a sliding 3D kftransform. Dip information opens a whole category of powerful dip-steered attributes and filters that are calculated in data-driven shapes such as 'warped' disks, cubes or slices.

\begin{tabular}{|l|}
\hline Energy \\
Frequency \\
Similarity \\
Continuity \\
Cube Similarity \\
Dip Variance \\
Azimuth Variance \\
Reference Time \\
\hline
\end{tabular}

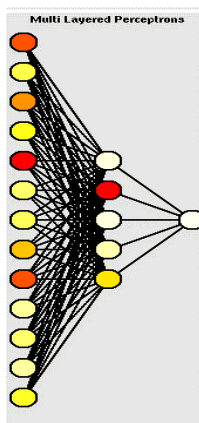

Chimney Probability

Figure 1- Input attributes to a MLP NN to obtain Chimney Probability.

Figure 1 demonstrates a typical set of input attributes to the neural network. The output of the network for each sample point is a value between 0 and 1 representing the chimney probability. Choosing a threshold value, one can create a binary value indicating presence or absence of chimneys. Colors associated with the input nodes indicate significance of the corresponding attribute or their discriminatory power in the process. Application of the trained network yields the desired texture enhanced volume in which the desired objects can be detected more easily. Figure 2 shows a time slice of a chimney cube. High chimney probability areas are mostly circular features at the intersection of the inline and crossline as well as those to the right. 


\section{Chimney interpretation}

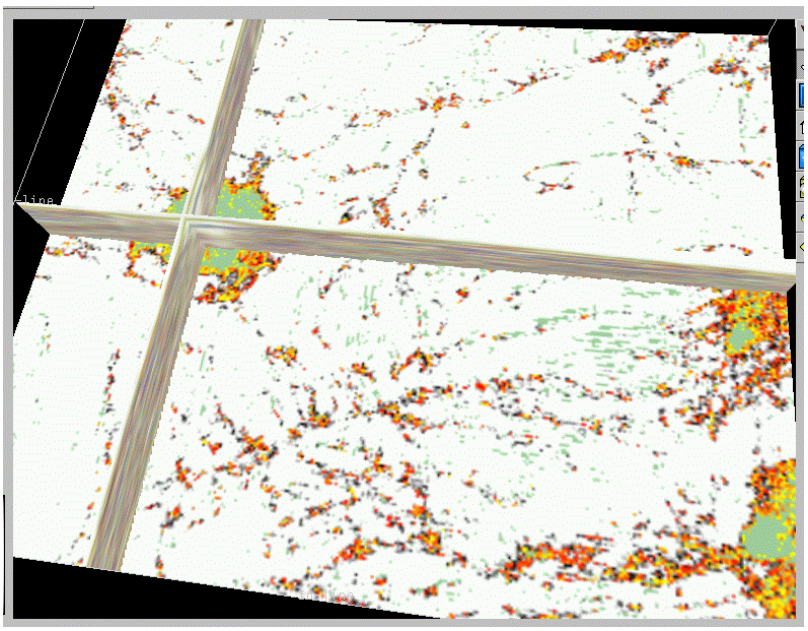

Figure 2- A chimney Cube slice

\section{Chimney interpretation}

Gas clouds or chimneys appear as low quality seismic response with vertical bodies of varying dimensions. Also shape and distribution may vary, although cigar-shapes and a distribution along faulted zones are common. The internal texture shows a chaotic reflection pattern of low energy. The exact outline of a chimney is very difficult to determine on conventional seismic displays. Only large chimneys can be recognized. To also detect more subtle disturbances we will transform the data into a new cube that highlights vertical disturbances. A neural network does this by classifying the data in two classes: chimney versus

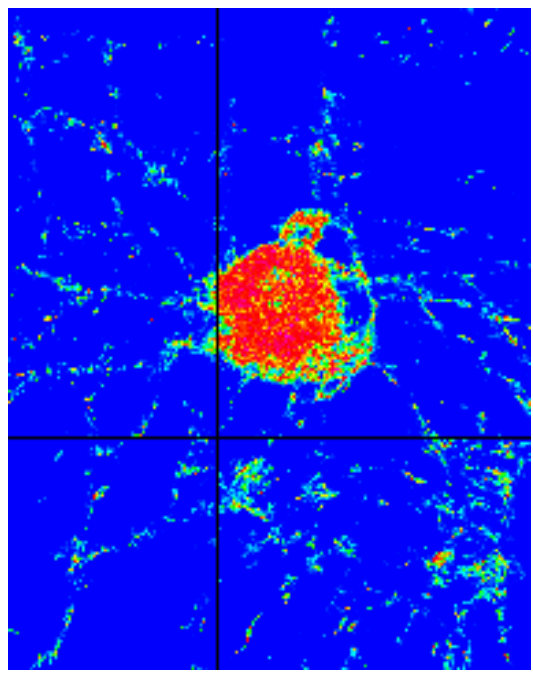

Figure 3-Example of radial patterns in a chimney slice non-chimney. Example locations are chosen inside interpreted chimneys as well as outside. Chimneys, in most cases, also demonstrate radial patterns on time slices of chimney cubes, Figures 2 and 3. The friction generated from vertical migration of hydrocarbons and possible fracturing of near by rocks causes this. These fractured rocks are subsequently filled with hydrocarbons. Once the chimneys are identified, they can be displayed in conjunction with the structural model or other reservoir property information. This helps validating certain geological interpretation such as the origination.

\section{Selected Case Histories of Chimney Applications}

\section{1- West Africa Case History: Support Charging of} Shallow Reservoirs \& Determining Migration Path

Chimney cube data can often show charging of shallow reservoirs. In this example from deepwater, Nigeria the risk for hydrocarbon charge into a shallow reservoir objective was constrained using chimney cube data (Figure 4). Possibly more significant, the chimney processing showed an absence of vertical charge into a number of up-thrown closures, which had not undergone the same degree of structuring, and the risk for charge to these leads was correspondingly increased. In general, we are observing a strong correlation between high strain rates and vertical migration paths evidenced by chimneys. Chimney data has proven critical to understanding the migration path of hydrocarbons into shallow reservoir targets.

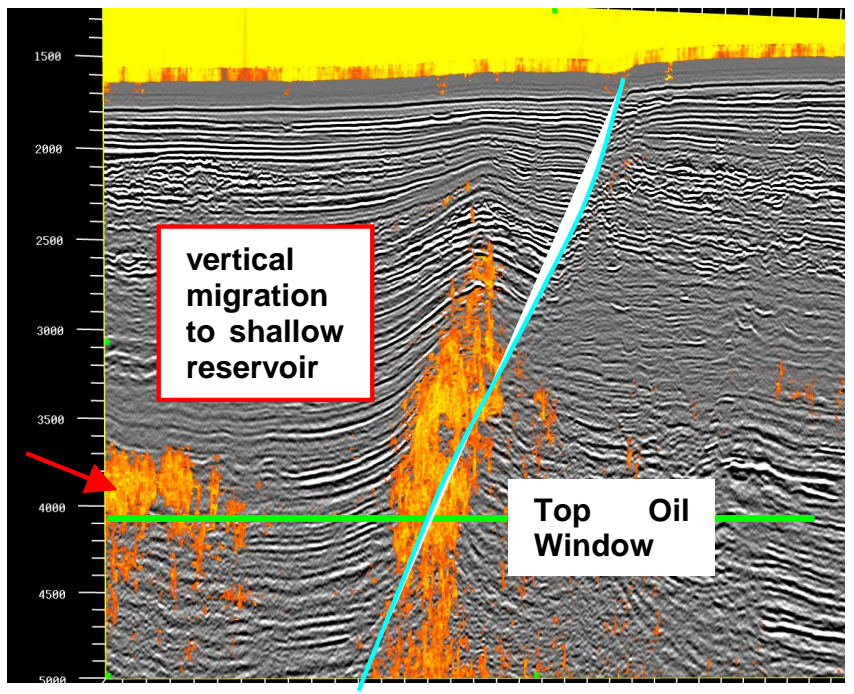

Figure 4 - Diffuse chimney character below a shallow reservoir objective. 


\section{Chimney interpretation}

\section{2- Gulf of Mexico Case History- Distinguishing Slow Seepage Versus Rapid Venting}

Roberts (2001) has contrasted the acoustic response of a number of shallow subsurface acoustic wipe-out zones ("gas chimneys") in the northern Gulf of Mexico upper continental slope. He collected data on 29 features, using high resolution seismic, side-scan sonar, 3D-seismic, and direct seafloor verification. Feature types were grouped into those that are a result of rapid delivery or venting of fluids and gases at one end of the spectrum and those that are the result of slow seepage on the other. The rapid delivery features are mud-prone while the slow delivery features are mineral-prone.

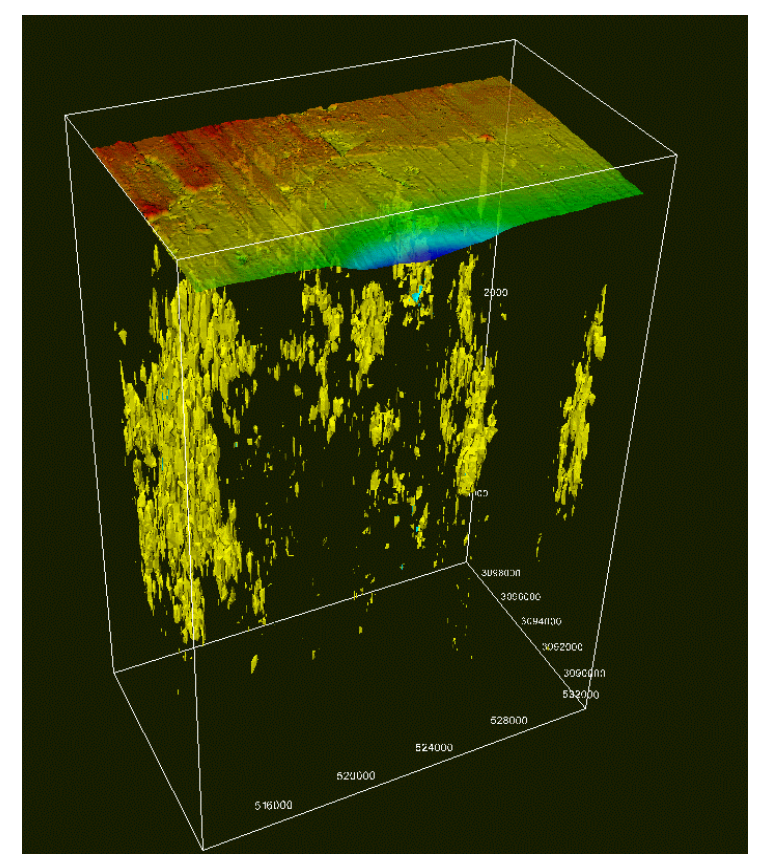

Figure 5- Chimneys Indicting Slow Seepage Versus Rapid Venting

Irregular mounds with a high degree of surface roughness characterize the seafloor of the mineral-prone features. On 3D-seismic, mineral-prone seafloor is highly reflective compared to surrounding seafloor. However the 3D-seismic across the features shows no phase reversal. In the subsurface acoustic windows can occur between mounds and thus the seismic has a somewhat chaotic signature. In contrast the mud-prone features have a more smooth surface texture, often have rather concentric patterns since they generally originate from a central vent. On 3D-seismic surface amplitude data active mud vents strongly deviate from background and display a positive-to-negative polarity shift. Figure 5 taken from Aminzadeh et al (2001) shows both slow seepage and those with rapid venting from a Gulf of Mexico field. There are possible textural and acoustic attribute differences between these mineral-prone seeps and the mud-prone vents. Consequently, the object detection methodology should help distinguish these two end members as well as the transitional cases. Additional work utilizing conventional seismic and velocity data on these Gulf of Mexico examples could prove to be very valuable.

\section{3-West Africa Case History, Distinguishing Active Fault Migration Pathways}

Actively seeping faults at the seafloor often have a very recognizable character. Such hydrocarbon seeps, as indicated from piston core data, are represented by small scale fault related pockmarks and large scale mud volcanoes. A time-slice from chimney cube data shows the pockmark character (Figure 6). Piston core data in the area indicates both oil and gas seepage. Many basins, such as the Gulf of Mexico, are essentially undercharged, and migration of hydrocarbons via faults is dominant. Understanding which faults are the major hydrocarbon conduits is critical to high-grading the fault blocks as drilling prospects.

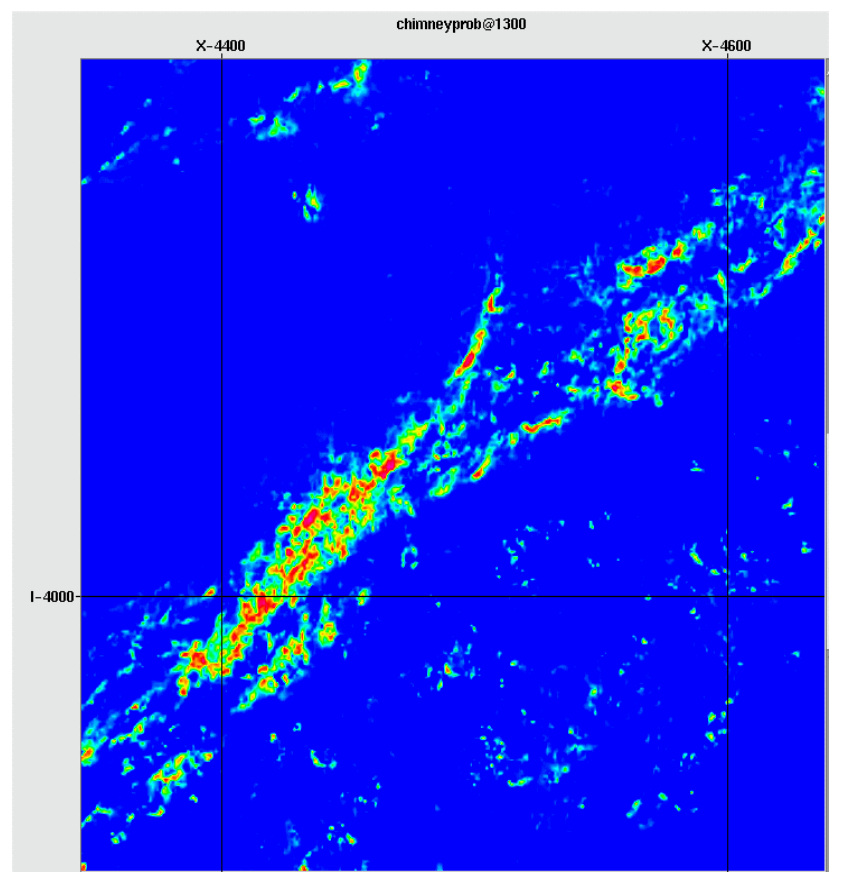

Figure 6- Linear fault related gas chimneys in the shallow subsurface 


\section{Chimney interpretation}

\section{4- Distinguishing Oil-prone Versus Gas-prone Prospects}

It is critical to distinguish oil-prone versus gas-prone prospects. The traditional tools to predict hydrocarbon phase include source rock facies variations (based on piston core data and well geochemical data), structural timing variations (based on 2D and 2⿺辶2 2 -basin modeling), and geophysical modeling. Geochemical and timing variations are often ambiguous, especially when the source kitchen is in the gas window. Geophysical modeling is often not diagnostic in areas lacking well control.

Understanding trap integrity and its resultant effect on gas chimney character is a more promising approach. This model is based on Sales(1997) and O'Brien(1998) Traps can be divided into three main categories:

$x \square$ Class 1 - High Integrity Trap (Gas Prone) Seal capacity for gas and oil is greater than closure, thus traps spill oil and trap gas.

$x \square \quad$ Class 2 - Moderate to High Integrity Trap (Gas / Oil Prone) Seal capacity equals closure, thus traps leak gas.

$x \square$ Class 3 - Moderate Integrity Trap (Oil Prone) Seal capacity is less than closure, thus trap leaks gas and minor oil.

For low Integrity Traps seal capacity is much less than closure, and thus the trap has been breached. The category in which a prospect falls is often difficult to predict predrill. The character of the gas chimneys is often a key clue to make this determination. By combining chimney cube data with trap geometry, most likely hydrocarbon fill (from amplitude anomalies, pressure data, or regional data), and piston core or other surface geochemical data, semiquantitative predictions of hydrocarbon phase can be made. A summary of the model is shown in the table below:

\begin{tabular}{|l|l|l|l|}
\hline Type Trap & Major Product & Chimney Character & Piston Core \\
\hline High Integrity & Gas & Weak or diffuse & Minor gas seeps \\
\hline Moderate Integrity & Oil & Strong active & Gas or oil seeps \\
\hline Low Integrity & Dry Hole & Strong relict & Weak active seeps \\
\hline
\end{tabular}

Table 1- A Summary of the model

\section{Conclusions}

Based on many case histories we conclude that chimney interpretation is a valuable tool in many areas. Applications include: relating surface seeps to subsurface structures and reservoirs, understanding the hydrocarbon history model and the migration path, ranking prospects, detecting reservoir leakage, spill points \& sealing versus non-sealing faults, assisting in identifying potential over-pressured zones \& drilling (shallow gas) hazards, and assessing the sea floor stability for platform design and drilling.

\section{References}

Aminzadeh, F., Berge, T., B., de Groot, P. and Valenti, G., 2001, Using Gas Chimneys as an Exploration World Oil May and June Issues, pp 50-56 and pp 69-72.

Connolly, D. L. , Aminzadeh, F., de Groot, P., Ligtenberg, H., and Sawyer, R., 2002, Gas Chimney Processing as a New Exploration Tool: A West Africa Example, Proceedings of AAPG ,, Houston, March 11, 2002.

Dunbar, T., Hofland, G. and Davis, B., 1998, 3D Depth Imaging Through a Gas Cloud Using a Phased Velocity
Modelling Approach, 60th Mtg.: Eur. Assn. Geosci. Eng., Session:01-44.

Englehart, T., Randazzo, S., Bertagne, A. and Cafarelli, B., 2001, Interpretation of four-component seismic data in a gas cloud area of the central Gulf of Mexico: The Leading Edge, 20, no. 4, 400-408

Meldahl, P., Heggland, R., Bril, B., and de Groot, P., 2001. Identifying Fault and Gas Chimneys Using MultiAttributes and Neural Networks, The Leading Edge of Geophysics, pp. 474-482.

O'Brien, G.W., et.al., 1998. Evaluating Trap Integrity in the Vulcan Sub-basin, Timor Sea, Australia, using Integrated Remote-sensing Geochemical Technologies. In Purcell, P.G. and Purcell, R.R. (ed.) The Sedimentary Basins of W Australia 2: Proceedings West Australia Basin Symposium Perth Western Australia, 1998, p.237-254.

Sales, J.K., 1997. Seal strength vs. Trap Closure - A Fundamental Control on the Distribution of Oil and Gas. In Surdam, R.C., ed., Seals, Traps, and the Petroleum System, AAPG Memoir 67, p. 57-83.

Roberts, H.H., 2001. Improved geohazards and benthic habitat evaluations: digital acoustic data with ground truth calibrations. OCS Study MMS 2001-050. U.S. Dept. of the Interior, Minerals Mgmt. Service, Gulf of Mexico OCS Region, New Orleans, La. 116 pp+ appendices. 